Bangladesh J. Pl. Breed. Genet., 28(2): 01-07, 2015

\title{
G $x$ E INTERACTION OF YIELD AND YIELD CONTRIBUTING CHARACTERS IN CHILLI (Capsicum frutescens L.) USING AMMI MODEL
}

\author{
A. A. Noman, M. S. R. Bhuiyan and M. S. Islam \\ Department of Genetics and Plant Breeding \\ Sher-e-Bangla Agricultural University, Dhaka 1207, Bangladesh
}

\begin{abstract}
Ten chili (Capsicum frutescens L.) genotypes were subjected to an experiment for analysis of stability and genotype-environment interaction in the randomized complete block design with four environments using additive main effect and multiplicative interaction (AMMI) model. Parameters for experimentation were number of fruits per plant, fruit diameter, leaf area index, fruit length without panicle, number of seeds per fruit and individual plant fruit yield. A significant mean sum of square due to Genotype $(\mathrm{G})$, Environment $(\mathrm{E})$ and $\mathrm{G} \times \mathrm{E}$ interaction for all the characters was showed by combined ANOVA, suggested differential responses of genotypes in different environments. The AMMI biplots for yield indicated that BD-2059 and Bogura Jatt were stable across the environments. Genotype Kalo Dhawna morich had positive interaction effect was better suited to the favourable environment for most of the traits. According to AMMI characterisation, Env-2 was found highly favourable for better expression of the studied traits for all the genotypes.
\end{abstract}

Key words: Chilli (Capsicum frutescens L.), AMMI, biplot analysis, G x E interaction

DOI: http://dx.doi.org/10.3329/bjpbg.v28i2.29959

\section{INTRODUCTION}

Chili is an important vegetable-cum-spice crop worldwide. It is an important cash crop of Bangladesh too (Ahmed and Haque, 1980). BARI has released only two varieties of chili, of which BARI Morich-1 is suitable for greater northern districts and other is only for the kharif season (Krishi Projukti Hatboi, 2015). But those can be seen minor in the farmer's field since they show less productivity in the variable environment like southern region (Sultana, 2007). Fertilizer dose is the probable cause of that problem. A decreasing trend in chilli production was found since 2011 (BBS, 2013). Lack of suitable varieties and increasing production cost are mostly the cause (Sultana, 2007). A country like Bangladesh, where the crops are grown in varied environmental conditions, stable genotypes are particularly of great importance. Stability is a genetic character of varieties which can be measured by determining interactions of varieties with locations, seasons (Tehlan, 1973) and different fertilizer rates (Gonsalves et al., 2009; Ma et al., 2004). Before recommending a new line to the farmer, it must be evaluated in trial testing the value of cultivation and use where fertilizer rate recommended is important (Gonsalves et al., 2009).

Various statistical techniques have been developed for describing $\mathrm{G} \times \mathrm{E}$ interaction, measuring genotypes stability, estimating the interaction level of genotypes to environments and eliminating unexplainable and extraneous variability in data content as much as possible. Among them, Finlay and Wilkinson model, (1963) and Eberhart and Russel model (1966) are noteworthy, where more efficient 
model to determine high yielder and most stable genotypes in multi-environment trials in comparison of previous procedures is AMMI model (Gauch, 1993). The biplot analysis is possibly the most powerful interpretive tool in AMMI model. $\mathrm{G} \times \mathrm{E}$ interaction is multivariate in nature. A yield trial that may have a $\mathrm{G} \times \mathrm{E}$ interaction, the appropriate statistical analysis is offered by AMMI model (Zobel et al., 1988). Encouraged by the above view, this study was undertaken to identify high yielder genotypes and to find out the most suitable fertilizer dose for chili to be adapted.

\section{MATERIALS AND METHODS}

Ten chili genotypes from different sources were used as experimental materials. This experiment was done at experimental field of Sher-e-Bangla Agricultural University, Dhaka-1207, Bangladesh. The experiment was scheduled in the randomized complete block design (RCBD) consisting three replications. The soil is characterized by brown to red, slight to strongly acid, finely structured, friable clay loams to clays (BBS, 2013). The field plot $(20.5 \mathrm{~m} \times 8 \mathrm{~m})$ was divided into 12 blocks $(4 \times 3)$ sized $4.25 \mathrm{~m} \times 1.6 \mathrm{~m}$, where treatments were randomly assigned. Then in each block, the genotypes were assigned randomly in 10 lines maintaining spacing $50 \mathrm{~cm} \times 45 \mathrm{~cm}$. Environments were created by different fertilizer doses, these are Urea + TSP + MOP + Gypsum $+\mathrm{ZnO}$ (Env-1), Urea + TSP + MOP + Cow dung (Env-2), Urea + TSP + MOP + Boric Acid (Env-3) and Cow dung (Env-4). Cow dung, Urea, TSP, MOP, Gypsum, $\mathrm{ZnO}$ and Boric Acid were used as per dose of 15 ton/ha, $275 \mathrm{Kg} / \mathrm{ha}, 200 \mathrm{Kg} / \mathrm{ha}, 200 \mathrm{Kg} / \mathrm{ha}, 20 \mathrm{Kg} / \mathrm{ha}, 10$ $\mathrm{Kg} / \mathrm{ha}$ and $10 \mathrm{Kg} / \mathrm{ha}$ respectively. Data were collected as per standard procedure on number of fruits per plant, fruit diameter, leaf area index, fruit length without panicle, number of seeds per fruit and individual plant fruit yield. Standard agronomic practices were followed as per soil test and required plant protection measures were taken.

The ANOVA was used and by AMMI model G x E interaction was estimated (Zobel et al., 1988). With this model, the contribution of every genotype and environment to $\mathrm{G} \times \mathrm{E}$ interaction can be measured by using the biplot graph where means of yield are plotted against IPCA1 scores (Zobel et al., 1988). The parameters of stability, the regression coefficient (bi) and the deviation from regression $\left(\mathrm{S}^{2} \mathrm{di}\right)$ were measured by Eberhart and Russell model (1966). The significance of differences between bi value and unity was tested by $\mathrm{t}$ test, among $\mathrm{S}^{2}$ di and zero by $\mathrm{F}$ test (Eberhart and Russell, 1966). In data analysis, cropstat 7.2 version statistical analysis package software (AMMI, SSA and ANOVA models) were used according to Zobel et al. (1988).

\section{RESULTS AND DISCUSSION}

The chili genotypes showed significant variations for all the characters indicating, the presence of genetic variability among the genotypes. The highly significant mean sum of squares owing to environments for all the traits indicated highly diverse environments and suitability to recommend fertilizer dose for the cultivation of genotypes. The $\mathrm{G} \times \mathrm{E}$ interactions for all the traits were found significant, which indicated significant differences between regression coefficients and that the extension of data for further stability analysis (Table 1). G x E interaction effects can be divided into three elements, $i e$, IPCA1, IPCA2 and IPCA3, here IPCA1 was different significantly. IPCA2 and IPCA3 were not significantly different. G x E (linear) has been found significant for all the traits indicated the linear relationship in the exposure of fruit yield with various environments (Table 1). These results are in agreement with the findings of Farshadfar and Sutka (2003).

The genotypes showing positive phenotypic index (Pi) with insignificant regression coefficient (bi) and deviation from regression $\left(\mathrm{S}^{2} \mathrm{di}\right)$, indicates the stability of 
genotypes over the environments (Kulsum et al., 2013). Kalo Dhawna morich showed positive $\mathrm{Pi}$, significant bi and insignificant $\mathrm{S}^{2}$ di indicating the high responsiveness to the rich environments. DBP 14 5G (China) and Suryamukhi showed negative phenotypic index, significant regression coefficient and insignificant $S^{2}$ di indicated the high responsiveness to the poor environments (Table 2). Tembhurne et al. (2013) found similar results on number of fruits per plant in chili. Positive Pi represents the higher fruit diameter and negative represents the lower. BD-2059 showed positive Pi, insignificant bi and $S^{2}$ di indicated genotype stability over all the environments with comparatively high fruit diameter. Any highly responsive genotypes couldn't be found to any environment. Tembhurne et al. (2013) found RCH-12 to be stable in case of fruit diameter in chili.

Table 1. Full combined analysis of variance including the separating of the $G \times E$ interaction of ten genotypes of chili

\begin{tabular}{l|c|c|c|c|c|c|c}
\hline Source of variation & df & $\begin{array}{c}\text { Fruits per } \\
\text { plant (no.) }\end{array}$ & $\begin{array}{c}\text { Fruit } \\
\text { dia. }(\mathrm{cm})\end{array}$ & $\begin{array}{c}\text { Leaf area } \\
\text { index }\end{array}$ & $\begin{array}{c}\text { Fruit } \\
\text { len.(cm) }\end{array}$ & $\begin{array}{c}\text { Seeds per } \\
\text { fruit (no.) }\end{array}$ & $\begin{array}{c}\text { Fruit yield } \\
\text { /plant (g) }\end{array}$ \\
\hline Genotype (G) & 9 & $20600.2^{* *}$ & $0.18^{* *}$ & $220.49^{* *}$ & $1.47^{* *}$ & $1998.55^{* *}$ & $14940.4^{* *}$ \\
Environment (E) & 3 & $18475.4^{* *}$ & $0.15^{*}$ & $119.19^{* *}$ & $4.41^{* *}$ & $183.40^{* *}$ & $41462.4^{* *}$ \\
Interaction (G×E) & 27 & $9009.87^{* *}$ & $0.07^{* *}$ & $29.99^{*}$ & $0.67^{*}$ & $27.36^{*}$ & $6627.60^{*}$ \\
AMMI component 1 & 11 & $9138.74^{* *}$ & $0.13^{* *}$ & $35.73^{*}$ & $1.10^{*}$ & $28.51^{*}$ & $6455.09^{*}$ \\
AMMI component 2 & 9 & 533.77 & 0.03 & 22.42 & 0.35 & 21.27 & 2528.68 \\
AMMI component 3 & 7 & 419.49 & 0.08 & 11.41 & 0.42 & 10.23 & 597.28 \\
G x E (Linear) & 9 & $10133.2^{* *}$ & $0.08^{*}$ & $38.60^{* *}$ & $0.64^{*}$ & $30.18^{* *}$ & $7226.45^{* *}$ \\
Pool deviation & 18 & 948.23 & 0.06 & 18.18 & $0.69^{*}$ & 16.95 & 1828.17 \\
Polled error & 105 & 3187.68 & 0.05 & 19.62 & 0.44 & 16.63 & 2999.63 \\
\hline
\end{tabular}

* and $* *$ indicates significance at $0.05 \%$ and $0.01 \%$ level, respectively.

For leaf area index, the genotype DBP 14 5G showed positive phenotypic index $(\mathrm{Pi})$, insignificant regression co efficient (bi) and deviation from regression $\left(\mathrm{S}^{2} \mathrm{di}\right)$ indicated genotype stability over all the environments (Table 2 ). Any highly responsive genotypes couldn't be found to any environment. Most of the genotypes showed low fruit length without panicle, only three showed higher fruit length. The genotype BD2059 showed positive phenotypic index $(\mathrm{Pi})$, insignificant bi and $\mathrm{S}^{2} \mathrm{di}$ indicating stable genotype over all the environments (Table 2). Kalo Dhawna morich showed positive phenotypic index $(\mathrm{Pi})$, significant regression coefficient (bi) and insignificant deviation from regression $\left(\mathrm{S}^{2} \mathrm{di}\right)$ indicated the high responsiveness for rich environment. BD-2122 showed negative Pi, significant bi and insignificant $S^{2}$ di indicated their suitability to the poor environment. These results are in agreement with Kulsum et al. (2013).

In the case of number of seeds per fruit, Suryamukhi showed positive phenotypic index $(\mathrm{Pi})$, nonsignificant regression coefficient (bi) and deviation from regression $\left(\mathrm{S}^{2} \mathrm{di}\right)$ which indicates that this genotype was stable over all the environments (Table 2). Bullet showed positive phenotypic index $(\mathrm{Pi})$, significant regression coefficient (bi) and insignificant deviation from regression $\left(\mathrm{S}^{2} \mathrm{di}\right)$ indicated their suitability to the rich environment. In the case of fruit yield (g) per plant (Table 2), the genotypes BD-2059 and Bogura Jatt showed positive phenotypic index $(\mathrm{Pi})$, insignificant regression coefficient and deviation from regression indicated comparatively stable genotype over all the environment. Five genotypes showed positive phenotypic index where others showed negative. Env-2 was found rich for higher fruit yield. Suryamukhi showed negative phenotypic index, significant $\mathrm{Bi}$ and insignificant deviation from regression indicated the suitability to the poor environment. These results agreed with the findings of Kulsum et al. (2013), Silveira and Vencovsky (1983) in case of rice grain yield. 
Table 2. Stability analysis for six characters in chili Stability analysis for six characters in chili Stability analysis for six characters in chili

\begin{tabular}{|c|c|c|c|c|c|c|c|c|c|c|c|c|c|}
\hline \multirow[t]{2}{*}{ Code } & \multirow[t]{2}{*}{ Genotype Name } & \multicolumn{4}{|c|}{ Fruits per plant (no.) } & \multicolumn{4}{|c|}{ Fruit diameter $(\mathrm{cm})$} & \multicolumn{4}{|c|}{ Leaf area index } \\
\hline & & Mean & $\mathrm{Pi}$ & bi & $\mathrm{S}^{2} \mathrm{di}$ & Mean & $\mathrm{Pi}$ & bi & $\mathrm{S}^{2} \mathrm{di}$ & Mean & $\mathrm{Pi}$ & bi & $\mathrm{S}^{2} \mathrm{di}$ \\
\hline G1 & Kalo Dhawna morich & 277.5 & 183.7 & $4.606^{*}$ & 3452.09 & 0.908 & -0.034 & 1.356 & 0.02 & 11.55 & -3.022 & 1.553 & 11.10 \\
\hline G2 & Bogurar Jhal Morich & 52.00 & -41.78 & -0.010 & 442.70 & 1.089 & 0.147 & 2.495 & 0.06 & 10.30 & -4.269 & 2.952 & 9.35 \\
\hline G3 & Balojhuri & 99.00 & 5.225 & 0.594 & 884.90 & 0.689 & -0.253 & -0.745 & 0.04 & 9.543 & -5.026 & 0.773 & 16.12 \\
\hline G4 & DBP 14 5G (China) & 50.25 & -43.53 & $0.407 *$ & 2.55 & 0.983 & 0.041 & 1.800 & 0.12 & 19.91 & 5.341 & 1.048 & 2.62 \\
\hline G5 & Suryamukhi & 37.25 & -56.53 & $0.139 *$ & 1.91 & 0.978 & 0.036 & 1.867 & 0.02 & 18.92 & 4.355 & 2.051 & 35.61 \\
\hline G6 & Bogurar lomba Morich & 147.8 & 53.97 & 1.434 & 1142.21 & 0.933 & -0.086 & 0.511 & 0.00 & 7.578 & -6.992 & 0.954 & 15.65 \\
\hline G7 & BD-2059 & 73.50 & -20.27 & 1.112 & 224.04 & 0.958 & 0.016 & 1.542 & 0.01 & 26.63 & 12.06 & 0.311 & 28.61 \\
\hline G8 & BD-2122 & 55.75 & -38.03 & 0.121 & 787.70 & 0.780 & -0.161 & -1.392 & 0.13 & 8.709 & -5.860 & 0.660 & 5.06 \\
\hline G9 & Bogura Jatt & 77.25 & -16.52 & 1.040 & 713.20 & 0.683 & -0.258 & 0.041 & 0.04 & 7.290 & -7.279 & 0.624 & 3.63 \\
\hline G10 & Bullet & 67.50 & -26.27 & 0.557 & 882.76 & 1.417 & 0.475 & 2.520 & 0.08 & 25.26 & 10.69 & -0.926 & 35.92 \\
\hline
\end{tabular}

Table 2. continued...

\begin{tabular}{|c|c|c|c|c|c|c|c|c|c|c|c|c|c|}
\hline \multirow[t]{2}{*}{ Code } & \multirow[t]{2}{*}{ Genotype Name } & \multicolumn{4}{|c|}{ Fruit length $(\mathrm{cm})$} & \multicolumn{4}{|c|}{ Seeds per fruit (no.) } & \multicolumn{4}{|c|}{ Fruit yield per plant (g) } \\
\hline & & Mean & $\mathrm{Pi}$ & bi & $\mathrm{S}^{2} \mathrm{di}$ & Mean & $\mathrm{Pi}$ & $\mathrm{Bi}$ & $\mathrm{S}^{2} \mathrm{di}$ & Mean & $\mathrm{Pi}$ & bi & $\mathrm{S}^{2} \mathrm{di}$ \\
\hline G1 & Kalo Dhawna morich & 4.264 & -0.504 & 0.984 & 1.13 & 48.69 & -32.46 & 0.71 & 20.37 & 196.5 & 83.94 & 2.38 & 3325.26 \\
\hline G2 & Bogurar Jhal Morich & 4.311 & -0.457 & 0.345 & 0.13 & 62.03 & -19.12 & $0.04 *$ & 0.59 & 64.29 & -48.24 & 0.231 & 869.68 \\
\hline G3 & Balojhuri & 4.494 & -0.274 & 0.629 & 0.42 & 71.22 & -9.928 & -0.038 & 7.92 & 89.33 & -23.21 & 0.504 & 1195.25 \\
\hline G4 & DBP 14 5G (China) & 6.078 & 1.310 & 2.214 & 1.05 & 92.89 & 11.74 & 0.814 & 26.75 & 58.93 & -53.61 & 0.798 & 29.69 \\
\hline G5 & Suryamukhi & 4.719 & -0.486 & 0.384 & 0.82 & 86.83 & 5.683 & 0.767 & 11.63 & 64.22 & -48.32 & $0.317 *$ & 108.92 \\
\hline G6 & Bogurar lomba Morich & 5.039 & 0.271 & -0.034 & 0.77 & 107.1 & 25.93 & 2.080 & 64.94 & 223.5 & 111.0 & 1.937 & 2770.02 \\
\hline G7 & BD-2059 & 5.539 & 0.771 & 1.697 & 0.23 & 75.83 & -5.317 & 1.510 & 5.63 & 93.73 & 18.81 & 1.121 & 168.57 \\
\hline G8 & BD-2122 & 4.497 & -0.271 & $1.597 *$ & 0.02 & 89.78 & 8.628 & 1.513 & 5.61 & 53.82 & -58.72 & 0.256 & 682.30 \\
\hline G9 & Bogura Jatt & 4.389 & -0.379 & 1.130 & 0.36 & 57.56 & -23.59 & 0.584 & 5.74 & 120.4 & 7.833 & 1.065 & 165.37 \\
\hline \multirow[t]{2}{*}{ G10 } & Bullet & 4.350 & -0.418 & 1.052 & 0.97 & 119.6 & 38.43 & $1.813^{*}$ & 1.38 & 160.7 & 48.17 & 1.487 & 6103.44 \\
\hline & Grand mean & 4.768 & & & & 81.15 & & & & 112.5 & & & \\
\hline
\end{tabular}

$\mathrm{Pi}=$ Phenotypic index, bi = Regression coefficient, $\mathrm{S}^{2} \mathrm{di}=$ Deviation from regression, $*$ indicates slopes significantly different from the slope for the overall regression which is 1.0 


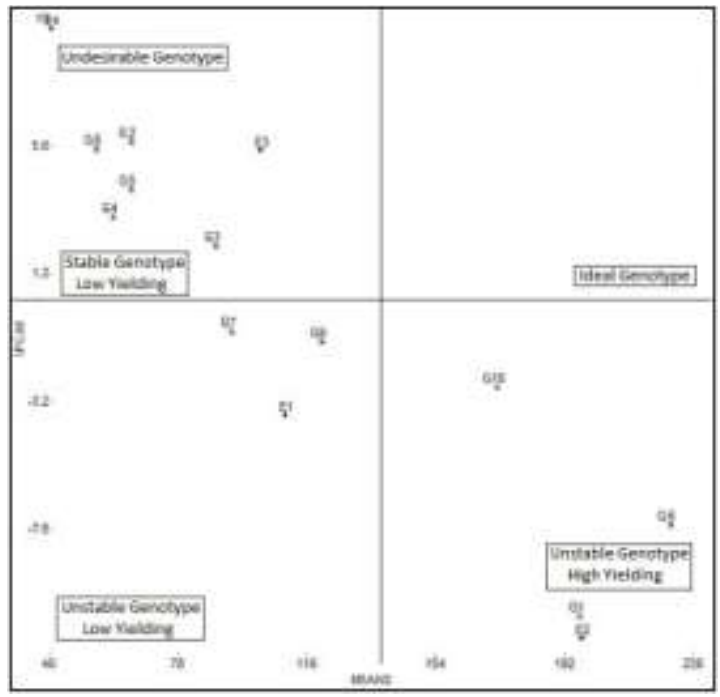

Fig. 1. Interaction biplot of of AMMI1 where IPCA1 score (Y-axis) plotted against mean yield ( $\mathrm{X}$-axis) for ten genotypes of chili.

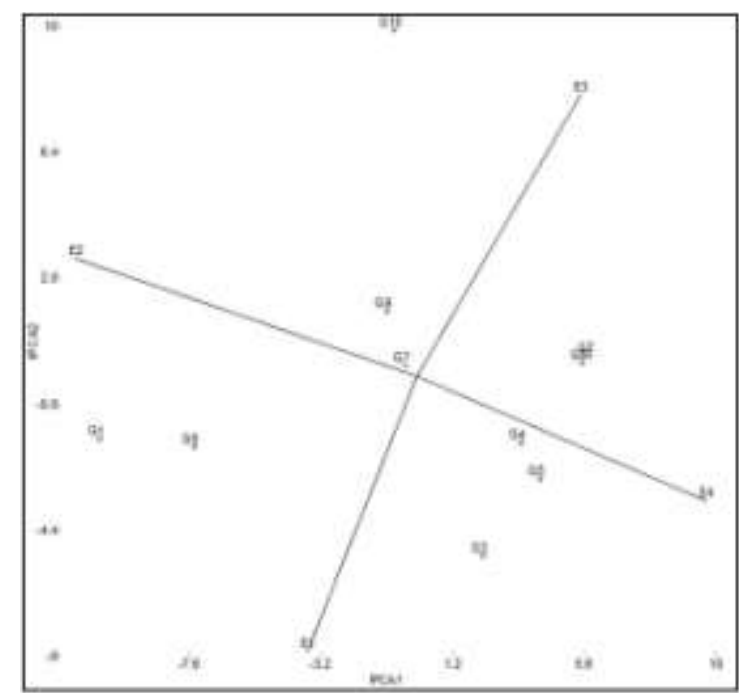

Fig. 2. Interaction biplot of AMMI2 where IPCA2 score (Y-axis) plotted against IPCA1 score ( $\mathrm{X}$-axis) for ten genotypes of chili.

Here, G1 = Kalo Dhawna morich, G2 = Bogurar Jhal Morich, G3 = Balojhuri, G4 = DBP 14 5G (China), G5 = Suryamukhi, G6 = Bogurar lomba Morich, G7 = BD-2059, $\mathrm{G} 8=\mathrm{BD}-2122, \mathrm{G} 9=$ Bogura Jatt, G10 =Bullet and E1 = Environment 1, E2 = Environment 2, E3 = Environment 3, E4 = Environment 4.

Environmental indices (Ij) in Table 3 indicate that, Env-2 was highly favorable for chili production for all the traits where Env-4 was found poor. Poor or unfavorable and Rich or favourable environments are reflected by negative and positive environmental index (Ij) for a character, respectively. Thus the Env-2 and Env-3 were found rich for higher fruit length and number of seeds per fruit. Env-1 and Env-2 were found rich for the higher number of fruits per plant and higher fruit diameter. Rapid fluctuation in temperature (average $20.6^{\circ} \mathrm{C}$ ) with an average rainfall $(14 \mathrm{~cm})$ during 
experimental period slowed the growth and caused early maturity and reduced yield. Although Kalo Dhawna morich and Bogurar lomba Morich were good yielders.

Table 3. Estimates of environmental indices (Ij) for six characters of chili under four different environments

\begin{tabular}{llccccc}
\hline Sl. & \multicolumn{5}{c}{ Environments } \\
\cline { 3 - 6 } no. & \multicolumn{1}{c}{ Characters } & Env-1 & Env-2 & Env-3 & Env-4 & Total \\
\hline 1 & Number of fruits per plant & 8.625 & 54.92 & -17.08 & -46.47 & -0.005 \\
2 & Fruit diameter & 0.103 & 0.469 & 0.117 & -0.174 & 0.515 \\
3 & Leaf area index & -0.21 & 4.871 & -1.589 & -3.075 & -0.003 \\
4 & Fruit length without & -0.185 & 0.823 & 0.131 & -0.773 & \\
& panicle & & & & -0.004 \\
5 & Number of seeds per fruit & 1.550 & 3.350 & 1.383 & -6.283 & 0 \\
6 & Individual plant fruit yield & -2.77 & 84.72 & -10.19 & -71.76 & 0 \\
\hline
\end{tabular}

The analysis by AMMIgives us a graphical image or biplot (Fig. 1) to make a summary of information on the main effects and the first interaction principle component axis score (IPCA1) of both genotypes and environments, at a time (Kempton, 1984). Displacement along the ordinate exhibits distinctions in interaction effects, where displacement along the abscissa reflects distinctions in main effects. The AMMI expected yield for any genotype and environment combination can be calculated from Fig. 1 following standard procedures suggested by Zobel et al. (1988).

Genotypes as well as environments, which situates on the identical parallel line, relative to the ordinate, have identical yields. Genotype or environment on the right side of the axis midpoint is high yielder than the counterpart. The genotypes Bullet, Bogurar lomba Morich and Kalo Dhawna morich were high yielding, with BD-2059 and Bogura Jatt being the moderate yielder. In contrast, Bogurar Jhal Morich, Balojhuri, DBP 14 5G (China), Suryamukhi and BD-2122 identified as low yielder. AMMI1 estimation had deep effect on producing ranking patterns clearly and tabular. On this basis BD-2059 and Bogura Jatt could be taken into consideration for more adaptability to a wide range of fertilizer dose than other genotypes. In case of, AMMI2 interaction biplot (Fig. 2), the more the position of a genotype towards the coordinate center, the more stable it is and vice versa. In that sense, BD-2059 and Bogura Jatt is also stable over environments. Dixon and Nukenine (1997) obtained a similar result in cassava genotypes. Genotypes which have a near zero IPCA1 score will endure meagre interaction over environments and vice versa with environments (Crossa et al., 1991). Positive specific interaction effects were produced by amalgamations with IPCA1 scores of the identical chord of Kalo Dhawna morich and Env-2.

\section{REFERENCES}

Ahmed, M. S. and M. A. Haque. 1980. Morphological characters and yields of five characters of chili. Bangladesh J. Hort. 8(1): 13-16.

Anonymous. 2013. Plant Genetic Resource Centre and Horticulture Division, Bangladesh Agricultural Research Institute (BARI), Gazipur. Supreme Seed Company Ltd., Mymensingh.

BBS. 2013. Statistical Year Book. Bangladesh Bureau of Statistics. Statistics division, Ministry of planning, government of the people's republic of Bangladesh, Dhaka, Bangladesh. 
Crossa, J., P. N. Fox, W. H. Pfeiffer, S. Rajaram, and H. G. Gauch. 1991. AMMI adjustment for statistical analysis of an international wheat yield trial. Theor. Appl. Genet. 81: 27-37.

Dixon, A. G. O. and E. N. Nukenine. 1997. Statistical analysis of cassava yield trials with the additive main effects and multiplicative interaction (AMMI) model. African J. Root Tuber Crops. 3: 46-50.

Eberhart, S. A. and W. A. Russel. 1966. Stability parameters for comparing varieties. Crop Sci. 6:36-40.

Farshadfar, E. and J. Sutka. 2003. Locating QTLs controlling adaptation in wheat using AMMI model. Cereal Res. Comm. 31: 249-255.

Finlay, K. W. and G. N. Wilkinson. 1963. The analysis of adaptation in a plant breeding program. Australian J. Agril. Res. 14: 742-754.

Gauch, H. G. 1993. Matmodel Version 2.0: AMMI and related analysis for two-way data matrices. Micro computer Power, Ithaca, New York, USA.

Gonsalves, R. J. S., A. F. B. Abreau, , M. A. P. Ramalho and A. T. Bruzi. 2009. Strategies for recommendation of common bean lines tested for value of cultivation and use in different environments. Crop Bred. and Appl. Biotech. 9:132-139.

Kempton, R. A. 1984. The use of biplots in interpreting variety by environment interactions. J. Agril. Sci. 103: 123-135.

Krishi Projukti Hatboi. 2015. Bangladesh Agricultural Research Institute (BARI). Pp: 190-199.

Kulsum, M. U., M. J. Hasan, A. AKTER, H. Rahman and P. Biswas. 2013. Genotypeenvironment interaction and stability analysis in hybrid rice: an application of additive main effects and multiplicative interaction. Bangladesh J. Bot. 42(1): 73-81.

Ma, B. L., W. Yan, L. M. Dwyer, J. Fre'geau-Reid, H. D. Voldeng, Y. Dion and H. Nas. 2004. Graphic analysis of genotype, environment, nitrogen fertilizer, and their interactions on spring wheat yield. Agron. J. 96:169-180.

Silveira, E. P. and R. Vencovsky. 1983. Grain yield stability of upland rice (Oryza sativa L.) in Sao Paulo State. Ciencia-e-Cultura. 35: 971-977.

Sultana, M. N. 2007. Genetic divergence of chilli (Capsicum frutescens L.)., M. Sc. Thesis, Depatment of Genetics and Plant Breeding. Sher-e-Bangla Agricultural University, Dhaka-1207.

Tehlan, R. S. 1973. Studies on production pattern and correlation in wheat. M. Sc. Thesis. Horiana Agril. Univ. Hissar, India.

Tembhurne, B. V. and S. K. Rao. 2013. Stability analysis in chilli (Capsicum annuum L.), J. Spices Aromatic Crop. 22(2): 154-164.

Zobel, R. W., J. M.Wright and J. H. Gauch. 1988. Statistical analysis of yield trial. Agron. J. 80: 388-393. 